\title{
Measuring equity market integration using uncorrelated information flows: Tokyo, London and New York
}

\author{
George Milunovich $^{\mathrm{a} *}$
}

\author{
Susan Thorp \\ ${ }^{a}$ Department of Economics, Macquarie University, Sydney NSW 2109 Australia \\ ${ }^{\mathbf{b}}$ School of Finance and Economics, University of Technology, Sydney Broadway NSW 2007 Australia
}

\begin{abstract}
Equity markets do not pass all overnight information into prices instantly at the opening of trade. We adjust open-to-close return series for non-instantaneous information absorption and then use adjusted series to measure integration among three major equity markets. Because the adjusted daytime return series are uncorrelated, we can accurately measure the size, and identify the sources, of transmissions. Overnight news, as represented by foreign open-toclose returns, explains 13\% of opening price variation (close-to-open returns) in New York, 14\% in Tokyo and 30\% in London. For New York and Tokyo, the largest influences come from the market that trades immediately prior (London and New York respectively) whereas opening price variation in London is linked closer with New York than Tokyo. Foreign volatility spillovers are also significant, and subject to asymmetric effects.
\end{abstract}

8 February 2007

JEL Classification: G14; G15

Keywords: Integration; Transmission; GARCH

\footnotetext{
*Corresponding author. Email address: gmilunov@efs.mq.edu.au Acknowledgments

The authors thank Minxian Yang and participants at the 13th Global Finance Conference (Rio de Janeiro, 2006), the 4th INFINITI Conference on International Finance (Dublin 2006), the Australasian Meetings of the Econometric Society (Alice Springs 2006), the Queensland University of Technology School of Economics and Finance Seminar and anonymous referees for helpful comments. Thorp is grateful for support from the Australian Research Council (ARC DP-0556775).
} 


\section{Introduction}

Variations in opening prices in the Tokyo, London and New York equity markets are significantly predicted by the returns and volatility patterns of overnight foreign trade. This predictability does not contradict market efficiency (since there is no opportunity to trade between the close and opening of a market), but it does identify the common information flows between the three markets, and offers a yardstick for measuring integration.

Using intra-daily data on the S\&P 500 (New York), the Nikkei 225 (Japan) and the FTSE 100 (London) indices, we search the early hours of trade in each market for the point of zero correlation with lagged foreign and domestic open-to-close returns. We make this the reference point for measuring the arrival of truly new information, and the starting point for adjusting returns calculations. We can then use the resulting zero-correlation open-to-close returns as explanators for opening price variation (close-to-open returns).

By isolating the early-trade 'opening' price which fully reflects preceding information, up to a one-half-hour interval accuracy, our new method improves the quality of integration measures for these markets. Other studies recognize that estimates based on raw opening prices are likely to mis-measure the size of transmissions between markets by omitting relevant information (see, for example, Baur and Jung 2006, Lin, Engle and Ito 1994 and Susmel and Engle 1994). Since our adjusted daytime returns are orthogonal explanatory variables in a model of opening price variation, we can identify both the size and the source of foreign market effects on price change and volatility with more ease and precision than when more arbitrary adjustments are made. ${ }^{1}$

Results show stronger and more significant mutual spillovers occurring between all three markets than have been reported previously. About $13 \%$ of the log change in close-toopening price in New York, 14\% in Tokyo and 30\% in London is explained by foreign

\footnotetext{
${ }^{1}$ Baur and Jung (2006) use similar search methods to compare the German and U.S. markets.
} 
daytime returns. The strongest impact on New York and Tokyo is from the markets that trade immediately prior to them, that is, London and New York respectively. London, however, appears to be much more dependent on New York’s daytime return than on Tokyo's, despite the fact that New York's news is older. Spillovers from foreign daytime volatility explain 9\% of opening price conditional variance in New York, 3\% in Tokyo and 2\% in London. We also find evidence of asymmetric effects in returns and volatility spillovers associated with negative foreign returns.

\section{Literature}

The degree of integration between international stock markets has long been recognized to have implications for portfolio allocation, risk management and asset pricing. Highly integrated markets offer reduced opportunities for diversification and may make the global financial system more susceptible to crisis. ${ }^{2}$ Studies of equity market integration aim to map the transmission of common information from one market to another through time. However, really precise mapping of information transmission is made difficult by the fact that continuously and randomly arriving news must be tracked using the non-synchronous and/or overlapping returns processes which we actually observe.

Past research into the transmission of shocks from one market to another has highlighted the importance of a careful treatment of returns timing, since results can be contaminated by nonsynchronous or overlapping measurement of returns (Martens \& Poon 2001).

Hamao, Masulis and Ng (1990, 1991) and Becker, Finnerty and Gupta (1990) approach the problem by dividing close-to-close returns (which confuse predictive and contemporaneous effects) into close-to-open and open-to-close returns. Becker, Finnerty and Gupta find a strong impact from lagged New York daytime returns to opening price changes in Tokyo, but a much weaker transmission from Tokyo to New York. In addition, using hourly data, Becker

\footnotetext{
${ }^{2}$ The extensive literature linking news and covariance includes, for example, King, Sentana and Whadwani (1994), Bekaert and Harvey (1995), and Bekaert, Harvey and Ng (2005).
} 
Finnerty and Tucker (1992) confirm that inter-market correlations can persist into the trading day beyond the initial opening, a feature which they attribute to a 'sticky' opening index value for Tokyo. However, filter tests indicate that the degree of return predictability uncovered in these studies was not sufficient to generate a profit net of trading costs. According to Jensen's (1978) version of the Efficient Markets Hypothesis (EMH), predictability in daily prices is consistent with the $\mathrm{EMH}$ as long as the patterns do not permit abnormal profits. Similarly, while Hamao, Masulis and Ng (1990), Engle, Ito and Lin (1990), and Lin (1989) show that volatility transmissions are significant, they do not find evidence that mean open-to-close returns could be predicted from one market to another.

Susmel and Engle (1994) concentrate on the hours when the London and New York markets trade simultaneously, searching for returns and volatility spillovers between contiguous segments of trade. Using hourly data from two years spanning the 1987 stock market crash, they find weak evidence of volatility spillovers, but no evidence of returns predictability. This is not surprising, given that news would be available to the markets almost simultaneously when both are trading, and would likely be incorporated into London and New York prices close in time. On the other hand, Baur and Jung (2006) investigate linkages between the U.S. and German stock markets, using high frequency data. They differentiate between contemporaneous correlations and lagged spillovers using specific definitions of intra-day and overnight returns. Over the January 1998 - December 2000 time frame, Baur and Jung find that foreign daytime returns can significantly influence domestic overnight returns, but find no evidence of spillovers between daytime returns.

Consistent with Hamao, Masulis and Ng (1990), Susmel and Engle (1994), our results confirm the weak and transitory nature of open-to-close returns spillovers into future open-toclose returns for these markets, and we reinforce (using filter trading rules) the fact that any predictability between daytime returns series is not commercially interesting. 
However Hamao, Masulis and Ng (1990) report that for London, New York and Tokyo, the daytime returns of at least one of the two foreign markets is significant in explaining the overnight (close-to-open) price variation of the third, and that at least one of the two will have a significant positive spillover in the conditional variance equation of the third.

Here we investigate the same three equity markets (over a different time period) and use a similar comparison between open-to-close and close-to-open returns, but our study differs from theirs in three respects. Firstly, we do not make a uniform fixed adjustment for 'stale' price effects at the beginning of trade. Instead we search the opening trading period for the point of full information absorption (within a 30-minute approximation), finding that it occurs much later in the trading day than the 15 minutes they allow for Japan, and much earlier than the noon opening they use for New York. Secondly, we explicitly model asymmetries in return and variance equations and find that both influence estimation results and spillover effects. Thirdly, the uncorrelated open-to-close returns series (information flows) we create allow us to break down the explained sum of squares in the overnight returns equation into components directly contributed by a specific foreign market.

\section{Method}

We contend that the impact of daytime returns and volatilities on opening prices (overnight returns) is important, since it defines the extent of stock market integration, and is best measured using returns series that fully embed prior information according to statistical significance. To illustrate this idea, consider the following scenario. Market A and Market B trade sequentially with no overlap in trading hours. Conventional measures of integration between $\mathrm{A}$ and $\mathrm{B}$ are computed by estimating the predictive power of news received during the trading day of A (overnight with regard to market B) for the opening price of Market B, and vice versa. If the trading-day news from A (measured as returns and volatility shocks) 
has significant predictive power for the opening price of $\mathrm{B}$, we conclude that information is shared between the markets and they are integrated to some degree.

However, consider the effects of small frictions which impede the speed with which Market B processes information from the trading day of Market A into prices. If the existence of frictions means that the opening price of Market B does not instantly and fully reflect the backlog of prior information, we may underestimate effects by using overnight (close-toopen) returns, leading us to conclude that integration is less important than it really is.

We approach this problem in two stages. First we establish the half-hour interval after opening where the index price embeds all information accumulated overnight, by modeling six sets of non-overlapping daytime ('open'-to-close) returns in a VAR-GARCH system. We measure non-overlapping daytime returns first at the initial opening price index value, and then in a sequence of five half-hour increments after the opening. We estimate the VARGARCH system using each returns series, and test for significant information transmission from market to market. Once a market has absorbed preceding news, estimated coefficients on all foreign returns and volatility spillovers will become statistically insignificant. Consequently, we can use significance tests to identify the point of time into the trading day (within a 30-minute band) when news from earlier trade in other markets is fully reflected in the domestic market price index.

We find that although the markets are efficient, they do not process all prior information instantaneously at opening. Returns from the previous day's trade in the other markets have explanatory power for domestic open-to-close returns for about 30 minutes in New York, about 90 minutes in Tokyo and for about 120 minutes in London. Volatility spillovers take longer to clear in all three markets.

At the second stage, having identified the average full-absorption 'opening' price in each market, we can measure information linkages and market integration by modelling the 
variation in 'opening' prices explained by foreign market news. Here we specify similar mean and variance equations as before, but the dependent variables are now the overnight (close-to-open) returns, and daytime returns are explanatory variables. For example, we measure the effects of foreign news by estimating the explanatory power of London and Tokyo daytime returns and volatility for the U.S. overnight return. A decomposed $R^{2}$ for each opening price variation equation gives the proportion of variation that is due to earlier daytime returns from each foreign market, and one-step-ahead variance decompositions likewise set out the impact of volatility spillovers.

\subsection{Data}

The Tokyo, London and New York stock markets open consecutively on any calendar day. We take half-hourly observations on the Nikkei 225, FTSE 100 and the S\&P 500 price indices, over the period January 5, 1996 - March 22, 2005, omitting all observations which fall on a non-trading day in any market. ${ }^{3}$

The Tokyo exchange, which opens first, has no concurrent trading with the other two exchanges. Tokyo trades from 7:00 p.m. to 9:00 p.m. and from 10:30 p.m. to 1:00 a.m. U.S. Eastern Standard Time (EST). London trades from 3:00 a.m. to 11:30 a.m. EST, and the New York Stock Exchange (NYSE) trades from 9:30 a.m. to 4:00 p.m. EST. New York and London share two hours of simultaneous trading between 9:30 a.m. and 11:30 a.m. (EST). We remove the effects of common trading hours between the London and New York markets by artificially ending the London day at 9:00 a.m. EST (2:00 p.m. London time), one half hour before the NYSE opens.

We compute six sets of daytime (open-to-close) returns $r_{t}^{(o+i)-c}$ for each market by holding the closing price $P_{t}^{c}$ fixed and moving the 'opening' price $P_{t}^{(o+i)}$ forward in 30-minute

\footnotetext{
${ }^{3}$ Intra-daily time series data were provided by SIRCA, http://www.sirca.com.au. All prices are measured in domestic currency. The S\&P 500 and FTSE 100 are market capitalisation-weighted and the Nikkei 225 is a price-weighted index.
} 
increments from the initial opening, so that: $r_{t}^{(o+i)-c}=\ln \left(P_{t}^{c} / P_{t}^{(o+i)}\right) \times 100$ where $i=\{0,30,60$, 90, 120, and 150$\}$ minutes. Similarly, we compute six series of overnight (close-to-open) returns $r_{t}^{c-(o+i)}$, taking the opening price over the previous day's closing price: $r_{t}^{c-(o+i)}=\ln \left(P_{t}^{(o+i)} / P_{t-1}^{c}\right) \times 100$, and again moving the 'opening' price forward through the day by 30-minute steps. As i increases, daytime returns cover a shorter, and overnight returns cover a longer, time period.

If markets incorporate information into prices instantly and freely, and trading hours are consecutive between markets, we would expect the daytime return from, say, New York, to have zero covariance with prior daytime returns from Tokyo and London, since each return will represent a separate, independent information flow (see the solid lines in Figure 1 below). On the other hand, we would expect overnight returns in New York to be predicted by the daytime returns of Tokyo and London, since they conduct business while New York is closed, and any overnight information that is common to Tokyo and/or London and New York needs to be incorporated into stock prices at the opening of the NYSE (see the dashed lines in Figure 1). The strength of return and volatility spillovers from foreign daytime returns into opening prices offers a measure of market integration. However, if the markets take some time to incorporate overnight information, initial opening prices will not fully represent news from other markets, daytime returns will have non-zero covariance with earlier foreign returns, and integration may be underestimated.

\section{[INSERT FIGURE 1 HERE]}

The moments of the adjusted returns series (Table 1) reveal part of the well-documented Ushape in intra-day volatility. We see that daytime returns calculated on the initial opening price have higher standard deviations than those beginning later in the day, and that volatility declines at a non-linear rate as the day progresses. Means and skewness coefficients confirm 
that the opening-price index value is also higher on average. Conventional models of asset returns based on regular random news arrival predict a linearly decreasing variance as $i$ increases, but the high and rapidly decreasing volatility we observe here is more consistent with a bunching of news at the opening of trade, followed by a short period of increased activity while the market processes overnight information.

\section{[INSERT TABLE 1 HERE]}

This pattern is repeated in reverse in the close-to-open returns series, and suggests that overnight news may not always be instantly and fully reflected in the first opening index value of a major market.

\subsection{Identifying uncorrelated information flows}

If the markets take time to absorb international news, then daytime returns computed using the initial opening price will be correlated across the markets. To test this hypothesis, we estimate a standard VAR-GARCH model with Glosten, Jagannathan and Runkle’s (1993) (GJR) asymmetry terms ${ }^{4}$ :

$$
\begin{aligned}
& r_{t}=c+\left(\Phi+\gamma I_{t-1}\right) r_{t-1}+\theta x_{t}+\varepsilon_{t} \\
& \varepsilon_{t}=H_{t} \eta_{t}
\end{aligned}
$$

where $\mathbf{H}_{\mathbf{t}}$ is a $(3 \times 3)$ diagonal matrix of conditional standard deviations.

Elements of the daytime returns vector $\mathbf{r}_{\mathbf{t}}=\left[\begin{array}{lll}r_{1, t} & r_{2, t} & r_{3, t}\end{array}\right]^{\prime}$ are ordered by calendar time, so that Tokyo comes first, followed by New York and London. $\boldsymbol{\Phi}$ and $\gamma$ are $(3 \times 3)$ coefficient matrices that reflect information spillovers in returns. Asymmetric spillover coefficients $\gamma$ are included to capture dynamics associated with negative shocks, since $\mathbf{I}_{\mathbf{t}}$ is a $(3 \times 1)$ indicator function vector whose elements $I_{j t}(j=1, \ldots, 3)$ are equal to one when the news shock $r_{j t}$ is negative, and zero otherwise.

\footnotetext{
${ }^{4}$ See, for example, Black (1976) and Bekaert and Wu (2000) on asymmetric effects in equity markets.
} 
The innovation vector $\boldsymbol{\varepsilon}_{\mathbf{t}}=\left[\begin{array}{lll}\varepsilon_{1 t} & \varepsilon_{2 t} & \varepsilon_{3 t}\end{array}\right]$ follows a vector GJR variance process with volatility spillovers. The standardised innovations $\boldsymbol{\eta}_{\mathbf{t}}$ are normal white noise with unit variances. The $(2 \times 3)$ coefficient matrix $\boldsymbol{\theta}$ captures weekday seasonality given by a $(2 \times 1)$ dummy vector $\mathbf{x}_{\mathbf{t}}$, where $x_{1 t}$ is one for Mondays and zero otherwise, and $x_{2 t}$ is one for Tuesdays and zero otherwise.

We estimate the elements of $\boldsymbol{\theta}$ associated with Monday dummies for the New York and London markets and the element related to the Tuesday dummy for the Tokyo market and set the other elements of $\boldsymbol{\theta}$ to zero. ${ }^{5}$ Time subscripts in (1) indicate the temporal ordering in trading hours of the three exchanges. The daytime return for each market is explained by the immediately preceding daytime returns for the other two markets, and its own lagged return. The conditional variance vector $\mathbf{h}_{\mathbf{t}}=\left[\begin{array}{lll}h_{1 t} & h_{2 t} & h_{3 t}\end{array}\right]^{\prime}$ is an asymmetric vector GJR $(1,1,1)$ process with volatility spillovers:

$$
\mathbf{h}_{\mathrm{t}}=\boldsymbol{\omega}+\left(\boldsymbol{\alpha}+\boldsymbol{\delta} \mathfrak{I}_{\mathrm{t}-1}\right)\left[\boldsymbol{\varepsilon}_{\mathrm{t}-1} \circ \boldsymbol{\varepsilon}_{\mathrm{t}-1}\right]+\boldsymbol{\beta} \mathbf{h}_{\mathrm{t}-1}+\chi \mathbf{x}_{\mathbf{t}}
$$

The ' $\circ$ ' operator is the element-by-element multiplication operator, $\boldsymbol{\omega}$ is a $(3 \times 1)$ vector of intercepts, $\boldsymbol{\alpha}$ and $\boldsymbol{\delta}$ are $(3 \times 3)$ matrices of symmetric and asymmetric volatility spillover coefficients and $\boldsymbol{\beta}$ is a diagonal $(3 \times 3)$ matrix of GARCH coefficients. We define the elements of the indicator function $\mathfrak{I}_{i t}$ at one for negative $\varepsilon_{i t}$, and zero otherwise, and define day-of-the-week dummies for Monday and Tuesday in $\mathbf{x}_{\mathbf{t}}$, with coefficients $\chi$, as for (1). Time indexing corresponds to the temporal ordering of trading.

We estimate this model for each of the six daytime returns series, beginning with initial opento-close returns and moving through to later periods of the day. Series with the same increment to opening time appear on both sides of the equations. After estimation, we can test

\footnotetext{
${ }^{5}$ See Gibbons and Hess (1981) for the Monday effect and Kato (1990) for the ‘Japanese-Tuesday’ effect.
} 
for significant spillovers in returns, and then isolate the point in each day where information from earlier international trade is fully processed into a market's price. For example, if estimated coefficients on the returns from prior trade in New York and London are insignificant explanators for the open +60 minutes Tokyo return, but significant for the initial open and open +30 minutes returns, then we can infer that information from international overnight news takes up to 60 minutes to be fully reflected in the Tokyo price index.

\subsection{Measuring integration}

We measure integration by regressing domestic market opening-price change, as captured by overnight returns, on lags of international and domestic market daytime returns. Because we choose the 'opening' price index that corresponds to complete information absorption for both daytime and overnight returns series, we can fully account for the impact of that previous news. By contrast, if we choose an 'opening' price that does not correspond to full information absorption, we may underestimate market integration. ${ }^{6}$ We then use these uncorrelated information flows to decompose the explained sum of squares so that we may identify the source and size of spillover effects between markets.

Overnight returns follow a vector GJR $(1,1,1)$ process in which the explanatory variables are daytime returns:

$$
\begin{aligned}
& \mathbf{r}_{\mathbf{t}}^{\mathrm{c}-\mathbf{0}^{*}}=\mathbf{k}+\left(\boldsymbol{\psi}+\lambda \mathbf{I}_{\mathbf{t}-1}\right) \mathbf{r}_{\mathbf{t}-1}^{\mathbf{0}^{*}-\mathrm{c}}+\rho \mathbf{x}_{\mathbf{t}}+\mathbf{u}_{\mathbf{t}} \\
& \mathbf{u}_{\mathbf{t}}=\mathbf{G}_{\mathbf{t}} \mathbf{v}_{\mathbf{t}} .
\end{aligned}
$$

$\mathbf{G}_{\mathbf{t}}$ is a (3x3) diagonal matrix of standard deviations. $\mathbf{r}_{\mathbf{t}}^{\mathbf{c}-\mathbf{0}^{*}}$ is a $(3 \times 1)$ vector of close-to-open returns which is specified in the temporal order of trading. The asterisk in the superscript indicates that we have chosen returns corresponding to the full-absorption opening price for each market. Explanatory variables $\mathbf{r}_{\mathbf{t}-\mathbf{0}}^{\mathbf{0}^{*} \mathbf{c}}$ are lagged values of daytime returns for each

\footnotetext{
${ }^{6}$ In addition, since the previous day's closing price appears as the denominator of the independent variable, our full-absorption daytime returns avoid a potential endogeneity problem.
} 
market, again corresponding to the full-absorption opening price in each market, and $\mathbf{x}_{\mathbf{t}}$ are day-of-the-week dummies, as defined in $(1){ }^{7} \boldsymbol{\psi}$ and $\boldsymbol{\lambda}$ are $(3 \times 3)$ coefficient matrices that reflect information spillovers in returns. Asymmetric spillover coefficients $\lambda$ capture dynamics associated with negative shocks: $\mathbf{I}_{\mathbf{t}}$ is a $(3 \times 1)$ indicator function vector whose elements $I_{j t}(j=1, \ldots, 3)$ are equal to one when the news shock $r_{j, t-1}^{o *-c}$ is negative, and zero otherwise.

The innovations vector $\mathbf{u}_{\mathbf{t}}$ is an asymmetric vector GJR $(1,1,1)$ process with volatility spillovers from daytime returns shocks. The standardised innovations $\boldsymbol{v}_{\mathbf{t}}$ are normal white noise with unit variances. We model a vector of overnight conditional variances, $\mathbf{g}_{\mathbf{t}}^{\mathbf{c}-\mathbf{0}^{*}}=\left[\boldsymbol{g}_{1 t}^{c-o^{*}}, \boldsymbol{g}_{2 t}^{c-o^{*}}, \boldsymbol{g}_{3 t}^{c-o^{*}}\right]$ ' as:

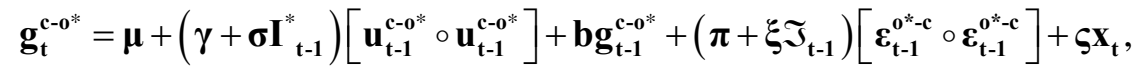

where $\boldsymbol{\mu}$ is a $(3 \times 1)$ vector of constants, $\boldsymbol{\gamma}$, and $\boldsymbol{\sigma}$ are diagonal matrices of symmetric and asymmetric ARCH terms, b is a diagonal matrix of GARCH coefficients, and $\boldsymbol{\pi}$ and $\boldsymbol{\xi}$ are $(3 \times 3)$ coefficient matrices of symmetric and asymmetric daytime volatility spillovers respectively. $\mathbf{x}_{\mathbf{t}}$ in (3) and (4) is a vector of day-of-the-week dummies as defined in (1), while $\boldsymbol{\rho}$ and $\varsigma$ are coefficient matrices that multiply the weekday dummies in the mean and variance equations respectively. The indicator function $\mathbf{I}_{t-1}{ }_{t-1}$ isolates negative close-to-open returns shocks where $I^{*}{ }_{i t}$ is one when $u_{i t}^{c-0^{*}}$ is negative, and zero otherwise.

We judge the effects of international equity market integration by the size and statistical significance of estimated spillover coefficients: $\boldsymbol{\psi}$ and $\boldsymbol{\lambda}$ in returns and $\boldsymbol{\pi}$ and $\boldsymbol{\xi}$ in volatility.

\section{Results}

\footnotetext{
${ }^{7}$ We also fit an MA(1) term in the mean equations (3).
} 


\subsection{Estimating predictability in daytime returns}

We begin by estimating the model in (1) and (2), and test for relevance of foreign and domestic return and volatility spillovers using Bollerslev-Wooldridge (1992) robust standard errors. ${ }^{8}$ Table 2 presents a summary of results.

\section{[INSERT TABLE 2 HERE]}

Tokyo receives information spillovers in daytime returns from both London and New York, as well as influences from its own previous day's return. The news from prior trade in London has predictive power for the Tokyo daytime return up to 30 minutes after opening. Tokyo’s own lagged daytime return has a significant and persistent negative coefficient, a feature which also shows up in London and New York. Tokyo receives volatility spillovers from New York, which are particularly strong for negative news shocks.

We infer that the Tokyo market processes all overnight information within the first 90 minutes of trading, so we use a price recorded 90 minutes after the opening time to represent the daily return for Tokyo.

The previous period's New York daytime return has predictive power for London returns, with a significant asymmetric component, for up to two hours, whereas the Tokyo return is not relevant. Volatility spillovers from Tokyo and New York are significant for conditional volatility predictions in London, also taking up to two hours to work through.

On the basis of these findings, we judge the London market to have processed all overnight news within 120 minutes after opening on average, and so we use the index value recorded at this time for the integration analysis that follows.

Returns on the S\&P 500 are predicted by overnight news emanating from London and Tokyo, but only for the first 30 minutes of trading. However, volatility spillovers from Tokyo and

\footnotetext{
${ }^{8}$ Detailed estimation results and diagnostics are available from the authors on request.
} 
London are predictive for the New York conditional variance for up to 150 minutes into the day.

Setting aside some volatility spillovers, the New York market absorbs foreign news quickly, and we select the open +30 minutes price index as an opening price reflecting overnight news. $^{9}$

On the face of it, results that indicate that stock market returns can be forecast using historical information appear to offer abnormal profit opportunities, and contradict the efficient markets hypothesis. Filter analysis (not reported here) confirms that the predictability we show is of no commercial interest, a fact which at least partly explains its persistence, since where any small gains exist they are almost certainly less than transaction costs. ${ }^{10}$ While commercially insignificant, the predictability we find is statistically relevant until our revised opening times. On the other hand, Table 3 shows that unconditional correlation estimates between daytime returns are effectively zero after adjustment. ${ }^{11}$

\section{[INSERT TABLE 3 HERE]}

\subsection{Estimating opening price variation}

Here we measure information transfer between markets via the impact of uncorrelated daytime returns and variances on domestic opening-price variation. Table 4 presents estimates of the model described by equations (3) and (4). Overnight news conveyed by foreign daytime returns significantly affects the adjusted opening price and opening price volatility in each market.

[INSERT TABLE 4 HERE]

\footnotetext{
${ }^{9}$ Baur and Jung (2006), investigating Frankfurt - New York linkages, also find overnight information processed within the first 30 minutes of New York trade.

${ }^{10}$ We conduct simple filter rules to test for commercial significance. A description of the filter rules and complete results are available from the authors on request.

${ }^{11}$ Sub-sample (periods before and after the March 24, 2000 'tech crash') estimations of information processing times, while not always the same, show no clear pattern of difference from the full sample results. Results are available from the authors on request.
} 
London and Tokyo daytime returns have a significant impact in New York, the stronger effect associated with the London return. New York also imports overnight volatility from Tokyo and London, the larger effect from London. $R^{2}$ indicates that about $13 \%$ of the total variation in the New York opening price is explained by the right-hand-side variables. ${ }^{12}$ Opening-price variation in Tokyo is related to prior returns from New York and London, as well as domestic market lags and effects from New York are particularly strong for negative returns shocks. We estimate that $12 \%$ of Tokyo opening price variation is explained by New York daytime returns, an estimate that is within the $11-18 \%$ range computed by Becker et al. (1992) for the 1985-1989 sample. Asymmetric volatility spillovers from New York and London are also significant (at 10\%) in the conditional variance estimates. In total, about 15 per cent of the variation in overnight returns in Tokyo is explained by the model.

The London stock market has the most predictable opening price variation: about 30 per cent is explained by the model. Predictive power comes mainly from Tokyo and New York daytime returns. ${ }^{13}$ In terms of volatility, London's conditional variance responds to asymmetric daytime volatility shocks from New York and lagged domestic daytime volatility.

Compared with related studies of the same three markets, these results indicate a larger number of significant linkages than previously observed. Hamao, Masulis and Ng (1990) find significant influence from U.S. daytime returns on the opening price in the U.K. and from the U.K. on the opening price in Japan for 1985-1988. Wei et al. (1995) study these markets over 1991-1993 and find mutual linkages between the daytime returns and opening price variation of the U.S. and the U.K., but not between these markets and Japan. By contrast, our results show significant linkages between returns in all three markets, along with a greater sensitivity

\footnotetext{
${ }^{12}$ New York is also the only market of the three that exhibits a statistically significant day-of-the-week effect. A positive coefficient in the close-to-open return implies that, on average, the opening price increased following a weekend.

${ }^{13}$ London overnight return is also dependent on its negative first order moving average term. This may indicate that London over-reacts to overnight news initially, but corrects the following day.
} 
to asymmetric effects. We also confirm significant volatility spillovers between all market pairs, qualified by somewhat weaker links between Tokyo and London, as do Hamao, Masulis and Ng (Wei et al. report fewer significant volatility spillovers). However, our findings indicate that asymmetric volatility spillovers are particularly important to international transmission.

\subsection{Decomposing the explained sum of squares}

When explanatory variables are correlated, it is difficult to allocate explanatory power among the regressors of a model, however, because we use adjusted 'opening' index values which embed prior information, regressors in equation (3) are uncorrelated (see Table 3 above). Table 5 reports the sources of explanation among the right-hand-side variables, showing the relative importance of information from each equity market. Of the $R^{2}$ of $12.90 \%$ for New York, $10.57 \%$ is explained by the daytime return in London, or just over $81 \%$ of the total. Of the remainder, $13.37 \%$ of the $R^{2}$ is attributable to the daytime return in Tokyo and $4.73 \%$ to New York’s own daytime return, a moving average term and a Monday dummy.

\section{[INSERT TABLE 5 HERE]}

The strongest influence on Tokyo's overnight return is also the market that trades immediately prior to Tokyo, that is, New York. About $81 \%$ of the total $15 \%$ of variation is due to daytime return in New York. The daytime return in London accounts for about $14 \%$ of $R^{2}$, while the remaining explanatory power is due to Tokyo's daytime return and a moving average term.

Unlike New York and Tokyo, London's overnight return has a closer link with a market that does not trade immediately prior. About $28 \%$ of the variation in its return is explained by the daytime return in New York and only $2 \%$ by the daytime return in Tokyo. This result 
suggests that Anglosphere linkages may be more influential for London than the timing of news arrival. ${ }^{14}$

We now turn to influences on conditional variance for each market (Table 6). Domestic market factors are the major influence on conditional returns variances in all three markets, but in terms of international volatility spillovers, New York exhibits the largest amount of predictability from foreign daytime volatility shocks. The volatility shock from London explains about 9\% of New York's one-step-ahead conditional variance, while the volatility shock from Tokyo explains only $0.5 \%$.

\section{[INSERT TABLE 6 HERE]}

Tokyo's conditional variance is largely unaffected by foreign daytime volatility shocks, with New York's and London's volatility spillovers accounting for only $2 \%$ and $1.5 \%$ of overnight conditional variance respectively. London's overnight conditional volatility is also mainly determined by its own volatility shocks, with New York explaining only about 2\%. In addition, any statistically significant foreign volatility spillovers in both London and Tokyo are associated with negative market news. ${ }^{15}$

\section{Conclusions}

We apply a new approach to gauging equity market linkages which allows for noninstantaneous adjustments to overnight news. The approach we adopt has several advantages over previously used methods. First, we explicitly test the data and ensure that foreign overnight news has been absorbed by the market price from which returns are computed before estimating financial market linkages, thus creating more accurate measures of return

\footnotetext{
${ }^{14}$ Estimation over pre- and post-tech bust periods (January 5, 1996 - March 24, 2000 and March 25, 2000 March 22, 2005) show that Tokyo’s dependence on London decreases slightly (from $15.4 \%$ to $9.4 \%$ of Rsquared in the first and second sub-samples). On the other hand, dependence of London on Tokyo increases (from $1.8 \%$ to $9.6 \%$ of R-squared). The comparable figures over the whole sample are $14 \%$ and $5 \%$ respectively. Results for New York are stable. Full sub-sample tables are available from the authors on request. ${ }^{15}$ Sub-sample estimation of variance effects are consistent with the full sample. Full sub-sample tables are available from the authors on request.
} 
and volatility spillovers. Secondly, this adjustment process means that daytime returns from domestic and international markets within the one 24-hour period are uncorrelated, a property that allows us to break down the incremental impact of news from each market. Thirdly, we account for asymmetric responses of conditional returns and variances to negative news from domestic and foreign markets.

Information transmission is mutual between all three markets; however, the strongest effects emerge from New York, followed by London (which explains more than $10.5 \%$ of New York's overnight return). Tokyo accounts for only 1.7\% of New York, and 2.1\% of London opening-price variation. Similar patterns hold for volatility: we find larger mutual interdependence between New York and London and only marginal spillovers from Tokyo.

Compared with earlier studies, we find that mutual linkages are more common and more significant. Results show that overnight foreign news might be a useful predictor of between 13 and $30 \%$ of domestic market price variation in these equity-trading centers. Similarly, high volatility days in major overseas markets, particularly when linked to negative returns shocks, point to a turbulent session in the coming day for the domestic market. Holders of internationally diversified portfolios can use such overnight information as a guide to portfolio rebalancing in the home market, or as a predictor of conditional volatility when reviewing risk-management. Overall, however, the extent of integration does not appear to eliminate advantages from international diversification, since the major proportion of domestic price variation remains unexplained.

\section{References}

Baur, D., Jung, R.C., 2006. Return and volatility linkages between the U.S. and German stock market. Journal of International Money and Finance 25, 508-613.

Becker, K.G., Finnerty, J.E., Gupta, M., 1990. The international relation between the US and the Japanese stock markets. Journal of Finance 45, 1297-1306. 
Becker, K.G., Finnerty, J.E., Tucker, A.L., 1992. The intraday interdependence structure between U.S. and Japanese equity markets. Journal of Financial Research. 15, 27-37.

Bekaert, G., Harvey, C., 1995. Time-varying world market integration. Journal of Finance 50, 403-44.

Bekaert, G., Harvey, C., Ng, A., 2005. Market integration and contagion. Journal of Business 78, 39-69.

Bekaert, G., Wu, G., 2000. Asymmetric volatility and risk in equity markets. Review of Financial Studies 13, 1-42.

Black, F., 1976. Studies of stock price volatility changes. Proceedings of the 1976 Meetings of the American Statistical Association, Business and Economical Statistics Section, 177181.

Bollerslev, T., Wooldridge, J.M., 1992. Quasi-maximum likelihood estimation and inference in dynamic models with time-varying covariances. Econometric Reviews 11, 143-172.

Engle, R.F., Ito, T., Lin, W-L., 1990. Meteor shower or heat waves. Heteroskedastic intradaily volatility in the foreign exchange market. Econometrica 55, 525-542.

Gibbons M., Hess, P., 1981. Day of the week effects and assets returns. Journal of Business 54, 579-596.

Glosten, L.R., Jagannathan, R., Runkle, D.E., 1993. On the relation between the expected value and the volatility of the nominal excess return on stocks. Journal of Finance 48, 17791801.

Hamao, Y., Masulis, R.W., Ng, V., 1990. Correlations in price changes and volatility across international stock markets. Review of Financial Studies 3, 281-307. 
Hamao, Y., Masulis, R.W., Ng, V., 1991. The effect of the 1987 stock crash on international financial integration. In: Ziemba, W., Bailey, W., Hamao, Y., (Eds.), Japanese Financial Market Research, Elsevier Science Publishers.

Jensen, M., 1978. Some anomalous evidence regarding market efficiency. Journal of Financial Economics 6, 95-102.

Kato, K., 1990. Weekly patterns in Japanese stock returns. Management Science 36, 10311043.

King, M., Sentana, E., Wadhwani, S., 1994. Volatility and links between national stock markets. Econometrica 60, 901-933.

Lin, W., 1989. The source of intra-daily volatility in the foreign exchange: a multivariate factor GARCH approach. Unpublished manuscript, Department of Economics, University of Wisconsin, Madison.

Lin, W., Engle, R.F., Ito, T. 1994. Do bulls and bears move across borders? International transmission of stock returns and volatility. Review of Financial Studies 7, 507-538.

Martens, M., Poon, S., 2001. Returns synchronization and daily correlation dynamics between international stock markets. Journal of Banking and Finance 25, 1805-1827.

Susmel, R., Engle, R.F. 1994. Hourly volatility spillovers between international equity markets. Journal of International Money and Finance 13, 3-25.

Wei, K.C.J., Liu, Y.J., Yang, C.C., Chaung, G.S., 1995. Volatility and price change spillover effects across the developed and emerging markets. Pacific Basin Finance Journal 3, 113136. 
Table 1

Summary statistics: daytime (open-to-close) stock index returns (\%)

\begin{tabular}{|c|c|c|c|c|c|}
\hline & Opening Times & Std. Dev. & Mean & Skewness & Kurtosis \\
\hline \multirow[t]{6}{*}{ New York } & Open & 1.145 & 0.025 & -0.092 & 5.480 \\
\hline & Open + 30 min. & 0.971 & 0.025 & 0.239 & 8.255 \\
\hline & Open + 60 min. & 0.896 & 0.037 & 0.196 & 7.277 \\
\hline & Open + 90 min. & 0.834 & 0.029 & 0.044 & 6.990 \\
\hline & Open + 120 min. & 0.789 & 0.034 & 0.061 & 5.784 \\
\hline & Open + 150 min. & 0.757 & 0.036 & 0.016 & 6.231 \\
\hline \multirow[t]{6}{*}{ Tokyo } & Open & 1.228 & -0.065 & 0.028 & 4.915 \\
\hline & Open + 30 min. & 1.044 & -0.042 & 0.208 & 5.053 \\
\hline & Open + 60 min. & 0.987 & -0.058 & 0.344 & 5.606 \\
\hline & Open + 90 min. & 0.909 & -0.050 & 0.096 & 5.219 \\
\hline & Open + 120 min. & 0.838 & -0.032 & 0.134 & 4.960 \\
\hline & Open + 150 min. & 0.837 & -0.035 & 0.120 & 4.960 \\
\hline \multirow[t]{6}{*}{ London } & Open & 0.862 & -0.019 & -0.671 & 8.602 \\
\hline & Open + 30 min. & 0.696 & -0.026 & -0.375 & 6.146 \\
\hline & Open + 60 min. & 0.626 & -0.018 & -0.304 & 5.397 \\
\hline & Open + 90 min. & 0.563 & -0.011 & -0.381 & 6.098 \\
\hline & Open + 120 min. & 0.506 & -0.008 & -0.368 & 6.081 \\
\hline & Open + 150 min. & 0.461 & -0.004 & -0.440 & 6.186 \\
\hline
\end{tabular}

The table displays summary statistics for daytime returns, $r_{t}^{i}=100 \times \ln \left(p_{t}^{c} / p_{t}^{(o+i)}\right)$, where $p_{t}^{c}$ is the index value at close of trade and $p_{t}^{(o+i)}$ is the index value recorded at the 'opening time' reported in column 2, of the S\&P 500 (New York), Nikkei 225 (Tokyo), and FTSE 100 (London). The sample runs from 5 January 1996 to 22 March 2005. 
Table 2

Duration of information relevance in daytime returns and volatility

\begin{tabular}{|c|c|c|c|}
\hline From/To: & Tokyo & London & New York \\
\hline \multicolumn{4}{|l|}{ Spillover in returns } \\
\hline Tokyo & > $150 \mathrm{~min}$. & - & $0 \mathrm{~min}-30 \mathrm{~min}$ \\
\hline London & 0 min. -30 min. & - & $0 \min -30 \min$. \\
\hline New York & $60 \mathrm{~min} .-90 \mathrm{~min}$. & $30 \mathrm{~min} .-60 \mathrm{~min}$. & - \\
\hline Tokyo Asymmetric & - & 一 & - \\
\hline London Asymmetric & - & 90 min. -120 min. & - \\
\hline New York Asymmetric & - & 90 min. -120 min. & $>150$ min. \\
\hline \multicolumn{4}{|l|}{ Spillover in variance } \\
\hline Tokyo & $>150$ min. & 90 min. -120 min. & 90 min. - 120 min. \\
\hline London & - & $>150$ min. & $>150$ min. \\
\hline New York & 30 min. - 60 min. & - & 0 min. -30 min. \\
\hline Tokyo Asymmetric & 90 min. -120 min. & 60 min. - 90 min. & $>150$ min. \\
\hline London Asymmetric & - & $>150$ min. & $>150 \mathrm{~min}$. \\
\hline New York Asymmetric & $30 \mathrm{~min} .-60 \mathrm{~min}$. & $0 \min -30 \min$. & $>150$ min. \\
\hline GARCH (1) & $>150$ min. & $>150$ min. & $>150$ min. \\
\hline
\end{tabular}

The table displays the results from estimation of the model given by equations(1) and (2) for each value of $i$, the increment after opening time at which daytime returns are computed. (Full estimation results are not reported here, but are available from the authors on request.) Cells show the period after the opening at which coefficients on spillovers from the previous day's returns or volatility from domestic and foreign markets become insignificant at the 10\% level using Bollerslev-Wooldridge standard errors. Empty cells show spillovers that are irrelevant for any i. ‘> 150 min’ indicates that estimated spillover coefficients do not become insignificant within the first 150 minutes of trading. 
Table 3

Unconditional (sample) correlation coefficients between daytime returns

\begin{tabular}{lccc}
\hline & New York & Tokyo & London \\
\hline New York & & 0.03 \\
Tokyo & \multirow{2}{*}{$* 00$} & -0.04 & $(0.19)$ \\
& & $(0.14)$ & 0.04 \\
London & & 1.00 & $(0.14)$ \\
& & & 1.00
\end{tabular}

The table displays sample unconditional correlation coefficients between adjusted daytime returns from New York, London and Tokyo. Returns are calculated as $r_{t}^{i}=100 \times \ln \left(p_{t}^{c} / p_{t}^{\left(0^{*}+i\right)}\right)$, where $p_{t}^{c}$ is the relevant equity index value at close of trade and $p_{t}^{\left(0^{*}+i\right)}$ is the index value recorded at the 'opening time' of 30 minutes after opening for New York, 90 minutes after opening for Tokyo and 120 minutes after opening for London. P-values are in brackets. 
Table 4

Significant information spillovers from daytime to overnight returns and volatility.

\begin{tabular}{|c|c|c|c|c|c|c|}
\hline & \multicolumn{2}{|c|}{ New York } & \multicolumn{2}{|c|}{ Tokyo } & \multicolumn{2}{|c|}{ London } \\
\hline & Coeff. & p-value & Coeff. & $p$-value & Coeff. & p-value \\
\hline \multicolumn{7}{|l|}{ Spillover in return from: } \\
\hline Tokyo $\psi_{1}$ & 0.11 & 0.000 & 0.14 & 0.010 & 0.12 & 0.001 \\
\hline London $\psi_{2}$ & 0.46 & 0.000 & 0.25 & 0.009 & 0.03 & 0.717 \\
\hline New York $\psi_{3}$ & 0.03 & 0.330 & 0.34 & 0.000 & 0.52 & 0.000 \\
\hline Tokyo Asymmetric $\lambda_{1}$ & 0.00 & 0.992 & -0.32 & 0.000 & 0.03 & 0.592 \\
\hline London Asymmetric $\lambda_{2}$ & 0.00 & 0.974 & 0.20 & 0.191 & 0.03 & 0.805 \\
\hline New York Asymmetric $\lambda_{3}$ & 0.00 & 0.979 & 0.21 & 0.025 & 0.13 & 0.074 \\
\hline Constant & 0.02 & 0.515 & 0.02 & 0.702 & 0.08 & 0.014 \\
\hline MA(1) & -0.05 & 0.057 & 0.03 & 0.129 & -0.09 & 0.000 \\
\hline Monday & 0.07 & 0.030 & - & - & 0.02 & 0.603 \\
\hline Tuesday & - & - & 0.00 & 0.973 & - & - \\
\hline \multicolumn{7}{|l|}{ Spillover in variance from: } \\
\hline Tokyo $\pi_{1}$ & -0.02 & 0.000 & 0.04 & 0.164 & -0.01 & 0.357 \\
\hline London $\pi_{2}$ & 0.19 & 0.057 & -0.06 & 0.171 & 0.00 & 0.971 \\
\hline New York $\pi_{3}$ & -0.01 & 0.192 & -0.01 & 0.673 & -0.01 & 0.282 \\
\hline Tokyo Asymmetric $\xi_{1}$ & 0.05 & 0.002 & -0.02 & 0.642 & 0.01 & 0.607 \\
\hline London Asymmetric $\xi_{2}$ & -0.04 & 0.724 & 0.14 & 0.066 & 0.27 & 0.002 \\
\hline New York Asymmetric $\xi_{3}$ & 0.05 & 0.003 & 0.05 & 0.085 & 0.05 & 0.073 \\
\hline Constant & 0.01 & 0.04 & 0.01 & 0.07 & 0.01 & 0.01 \\
\hline $\mathrm{ARCH}(1)$ & 0.03 & 0.50 & -0.01 & 0.20 & 0.01 & 0.39 \\
\hline ARCH(1) - Asymmetric & 0.03 & 0.55 & 0.08 & 0.00 & 0.08 & 0.00 \\
\hline GARCH(1) & 0.84 & 0.00 & 0.93 & 0.00 & 0.89 & 0.00 \\
\hline R-squared & $12.90 \%$ & & $14.99 \%$ & & $30.12 \%$ & \\
\hline \multicolumn{7}{|l|}{$\begin{array}{l}\text { Diagnostics on standardized } \\
\text { residuals }\end{array}$} \\
\hline Durbin-Watson stat & 2.04 & & 2.04 & & 2.03 & \\
\hline Ljung-Box (20) & 15.17 & 0.712 & 16.09 & 0.651 & 17.41 & 0.562 \\
\hline $\begin{array}{l}\text { Ljung-Box (20) } \\
\text { squared residuals }\end{array}$ & 6.75 & 0.995 & 15.56 & 0.687 & 10.69 & 0.934 \\
\hline Jarque-Bera & 7802.32 & 0.000 & 528.60 & 0.000 & 580.48 & 0.000 \\
\hline
\end{tabular}

The table displays estimated coefficients and p-values based on Bollerslev-Wooldridge (1992) robust standard errors of equations (3) and (4). $\psi_{i}$ and $\lambda_{i}$ are coefficients measuring information symmetric and asymmetric spillovers in returns. $\pi_{\mathrm{i}}$ and $\xi_{i}$ are coefficients measuring symmetric and asymmetric daytime volatility spillovers respectively. The estimation sample is from 6 January 1996 to 22 March 2005. 
Table 5

Decomposition of $\mathrm{R}^{2}$ in overnight returns equations

\begin{tabular}{lrrr}
\hline \multicolumn{1}{c}{ Dependent Variable: } & \multicolumn{3}{c}{ New York overnight return } \\
\hline Source of Variation & Explained SS & \% of explained \\
London & 132.08 & $10.57 \%$ & $81.90 \%$ \\
Tokyo & 21.56 & $1.73 \%$ & $13.37 \%$ \\
Subtotal London \& Tokyo & 153.64 & $12.29 \%$ & $95.27 \%$ \\
Other sources of variation & 7.63 & $0.61 \%$ & $4.73 \%$ \\
\cline { 2 - 4 } Total & 161.27 & $12.90 \%$ & $100.00 \%$ \\
\hline \multicolumn{1}{c}{ Dependent Variable: } & \multicolumn{3}{c}{ Tokyo overnight return } \\
\hline Source of Variation & Explained SS & $\%$ of explained \\
New York & 379.91 & $12.11 \%$ & $80.83 \%$ \\
London & 66.15 & $2.11 \%$ & $14.07 \%$ \\
Subtotal New York \& London & 446.06 & $14.22 \%$ & $94.90 \%$ \\
Other sources of variation & 23.96 & $0.76 \%$ & $5.10 \%$ \\
Total & 470.02 & $14.99 \%$ & $100.00 \%$ \\
\hline \multicolumn{1}{c}{ Dependent Variable: } & \multicolumn{3}{c}{ London overnight return } \\
\hline Source of Variation & Explained SS & & \% of explained \\
Tokyo & 44.26 & $1.50 \%$ & $4.99 \%$ \\
New York & 822.89 & $27.97 \%$ & $92.84 \%$ \\
Subtotal Tokyo \& New York & 867.15 & $29.47 \%$ & $97.84 \%$ \\
Other sources of variation & 19.16 & $0.65 \%$ & $2.16 \%$ \\
Total & 886.31 & $30.12 \%$ & $100.00 \%$ \\
\hline
\end{tabular}

The table displays the percentage breakdown in the explained sum of squares of the regression of overnight returns on lagged foreign (both symmetric and asymmetric effects) and domestic daytime returns, a constant and relevant day-ofthe-week dummies. 'Other' refers to an ma(1) term, the dependent variable’s own daytime return and day-of-the-week dummies (where statistically significant at 10\%). Where explanatory variables are uncorrelated, as in this case, the proportion of explained sum of squares (ESS) attributable to any explanatory variable $X_{i}$ is equal to $\hat{\beta}_{i}^{2} \sum_{t}\left(x_{i t}-\bar{x}_{i}\right)^{2}$ where $\hat{\beta}_{i}$ is the estimated coefficient on $x_{i}$, and $\bar{x}_{i}$ is the sample mean. We sum the symmetric and asymmetric daytime returns explained sum of squares for each market into one quantity when calculating the proportional impact of each source of shocks. For the asymmetric coefficients, the quantity $\sum_{t}\left(x_{i t}-\bar{x}_{i}\right)^{2}$ is computed using only negative returns shocks. 
Table 6

One-step-ahead opening price conditional variance decompositions

\begin{tabular}{cccc}
\hline & New York & Tokyo & London \\
\hline \hline Daytime volatility shock from: & & & \\
New York & $4.46 \%$ & $1.94 \%$ & $2.13 \%$ \\
Tokyo & $0.53 \%$ & $0.00 \%$ & $0.00 \%$ \\
London & $8.79 \%$ & $1.45 \%$ & $12.24 \%$ \\
Remainder (Domestic Overnight & & & \\
ARCH and GARCH) & $86.23 \%$ & $96.61 \%$ & $85.63 \%$ \\
Total & & & \\
\hline \hline
\end{tabular}

The table displays the proportions of one-step-ahead variance attributable to lagged foreign and domestic daytime volatility shocks. We set all conditional variance terms to their unconditional (sample mean) values and calculate the proportion of the total variance contributed by each spillover effect and by domestic ARCH and GARCH effects. For example, and ignoring asymmetric terms here for clarity, the one-step-ahead variance of the overnight return from (4) is given by $g_{i t}=\mu_{i}+\gamma_{i} u_{i t-1}^{2}+b_{i} g_{i t-1}+\sum_{j=1}^{3} \pi_{j} \varepsilon_{j t-1}^{2}$, where $\mu_{i}$ is the constant, $\varepsilon_{j t-1}^{2}$ represents a domestic or international daytime volatility spillover, $u_{i t-1}^{2}$ is a domestic overnight (ARCH) volatility shock and $g_{i, t-1}$ is the lagged domestic overnight GARCH variance. We compute the quantities in the table by substituting unconditional sample means for the values in the equation. Hence the proportional contribution of the daytime volatility spillovers to the total unconditional variance is $100 \times \pi_{j}\left(\frac{1}{T} \sum_{t=2}^{T} \varepsilon_{j, t-1}^{2}\right) / g_{i}$. We sum the symmetric and asymmetric volatility spillovers into one spillover quantity for each market when calculating these proportions, identifying the relevant $\varepsilon_{j, t-1}^{2}$ using the indicator function for negative returns. 
DAYTIME RETURNS

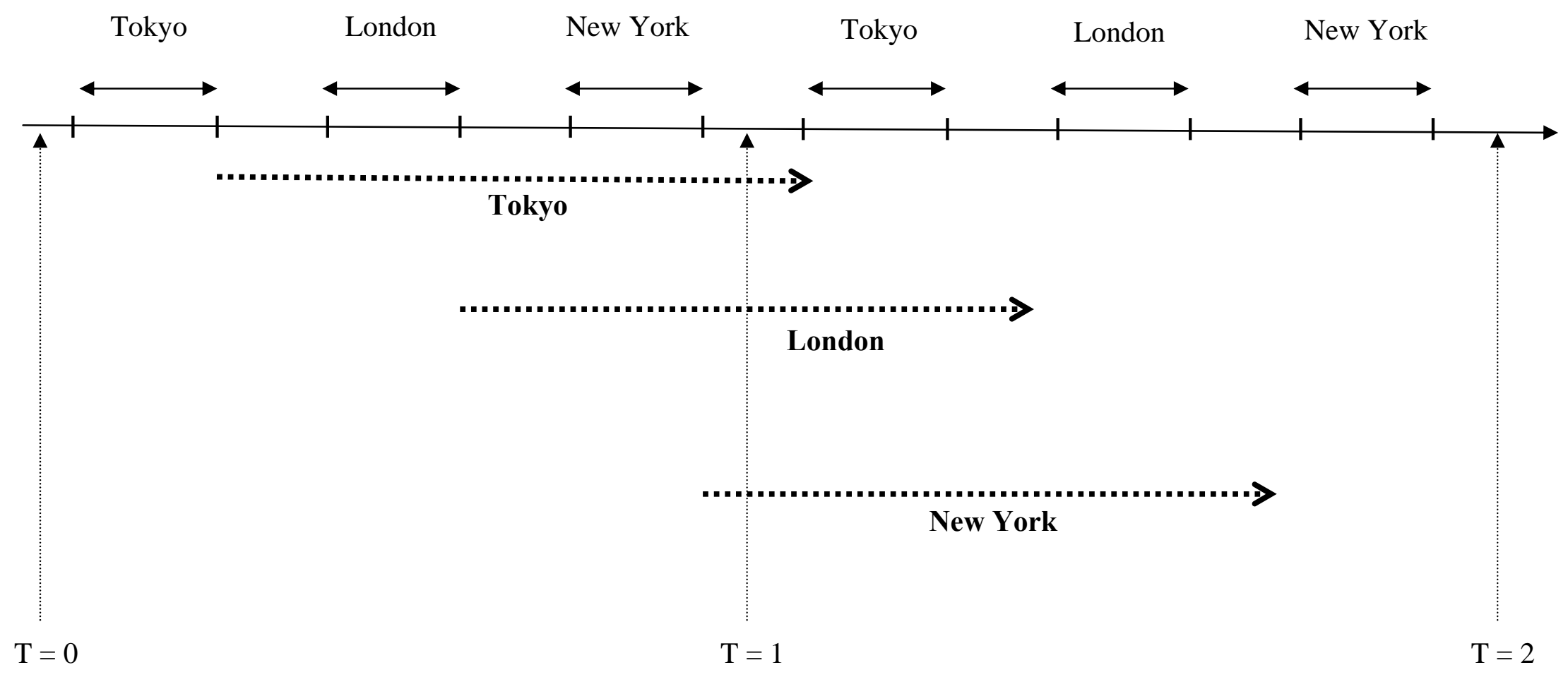

OVERNIGHT RETURNS 


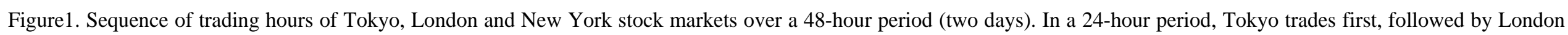

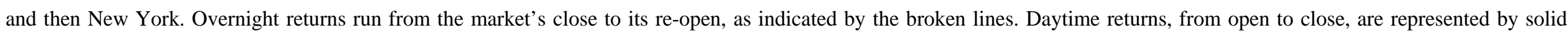
arrows. 